http://jmscr.igmpublication.org/home/

ISSN (e)-2347-176x ISSN (p) 2455-0450

crossref DOI: https://dx.doi.org/10.18535/jmscr/v8i1.127

Journal Of Medical Science And Clinical Research

\title{
Pharmacoepidemiology of Opthalmology Prescriptions
}

\author{
Authors \\ Dr Anupam Nath Gupta ${ }^{1}$, Dr Gangotri Barui ${ }^{2}$, Dr Paras Nath ${ }^{3}$ \\ ${ }^{1}$ Department of Pharmacology, North Bengal Medical College, Sushrutnagar, Darjeeling - 734012 \\ ${ }^{2}$ Department of Ophthalmology, North Bengal Medical College, Sushrutnagar, Darjeeling - 734012 \\ ${ }^{3}$ Department of Gynaecology and Obstretrics, Siliguri District Hospital, Darjeeling
}

\begin{abstract}
Introduction: Pharmacoepidemiology refers to the epidemiological methods to study the clinical use and effects/side effects of drugs. Drug utilization pattern needs to be evaluated from time to time so as to increase therapeutic efficacy and decrease adverse effects.

Material and Methods: Prescriptions of patients treated during the course of the study were audited retrospectively using a specially designed form to record the required information from the case sheets of each patient. All the drugs prescribed were recorded.

Results: The average number of drugs per prescription is 3.234, drugs prescribed by their generic name were 31.47. Regarding dosage form eye drop (80.67\%). Most frequently prescribed class of drug is antibiotics, mydriatics, anti-inflammatory.

Discussion: Pharmacoepidemiology is a powerful tool that can benefit patient and public health but only if used appropriately by providing the insights into various aspects of drug prescribing and drug uses. WHO organizes many drug utilization researches with the goal of rational prescription by various methods of auditing.

Conclusion: Improvement through continuous education is desired on the part of prescribers to ensure a good standard of care.
\end{abstract}

\section{Introduction}

Pharmacoepidemiology refers to the epidemiological methods to study the clinical use and effects/side effects of drugs in large numbers of people with the purpose of supporting the rational and cost effective use of drugs in the population. That's why drug utilization research has become an essential part of pharmacoepidemiology and together both provide the insights into various aspects of drug prescribing and drug use like pattern of use, quality of use, determinants of use and outcomes of use (WHO, 2003). ${ }^{1}$ Drug utilization pattern needs to be evaluated from time to time so as to increase therapeutic efficacy and decrease adverse effects. Hence periodical auditing of drug utilization pattern is vital for promotion of rational use of drugs, for increasing the therapeutic efficacy and the cost effectiveness, for decreasing the adverse effects and to provide feedback to the prescribers. $^{2}$

Drug therapy is a major component of patient care management in health care settings .Recently in the discipline of ophthalmology there have been many drug development and introduction of ocular therapeutics. Therefore the aim of this 
study was to define the pattern of drug utilization among ophthalmology patients it also serve as a vital exploratory tool to determine the safety and effectiveness of drugs along with improving the quality of drug therapy thus avoiding prolonged irrational use of drugs.

\section{Material and Methods}

The present study was conducted in the Department of Ophthalmology, North Bengal Medical College, Darjeeling. The required data was collected for a period of 6 month from the record section using appropriately designed Performa's. The data obtained from all the prescriptions was tabulated.

Prescriptions of patients treated during the course of the study were audited retrospectively using a specially designed form to record the required information from the case sheets of each patient. All the drugs prescribed were recorded including its dosage form, route of administration, frequency of administration, indications for which prescribed and duration of therapy. These forms were then used to analyze the average number of drugs per prescription, number of encounters with antibiotics, anti-inflammatory drugs and other agents, .Both males and females were included in the study who were diagnosed and treated in the Department of Ophthalmology , North Bengal Medical College, Darjeeling.

Selection Criteria: Patients of either sex and all ages treated in ophthalmology department

\section{Results}

After screening the 6 month a total of 5668 OPD patients among them 2930 male and 2738 female. In 5668 prescriptions 18334 drugs were prescribed. This shows that the average number of drugs per prescription is 3.234. Drugs prescribed by their generic name were $31.47 \%$ and $68.53 \%$ by their brand names. About $26 \%$ is dispensed by hospital .Regarding dosage form eye drop $(80.67 \%)$, eye ointment $(14.43 \%)$, oral $(3.11 \%)$ and parenteral (1.79\%). Most frequently prescribed class of drug is antibiotics, mydriatics, anti-inflammatory in combination with antibiotics followed by antibiotics with steroids and anesthetics. Other classes of drugs used are steroids, anti-inflammatory, antifungal, antivirus, lubricants and antiallergics.

Number of drugs prescribed per prescription

\begin{tabular}{|l|c|}
\hline $\begin{array}{l}\text { Number of drugs per } \\
\text { prescription }\end{array}$ & Number of prescriptions \\
\hline One & $2334(41.17 \%)$ \\
\hline Two & $1306(23.06 \%)$ \\
\hline Three & $608(10.72 \%)$ \\
\hline Four & $688(12.14 \%)$ \\
\hline Five & $348(6.13 \%)$ \\
\hline Six & $384(6.78 \%)$ \\
\hline Total & $5668(100 \%)$ \\
\hline
\end{tabular}

Formulation of medication

\begin{tabular}{|l|c|}
\hline Formulation of Drug & Percentage of prescriptions \\
\hline Eye drop & 80.67 \\
\hline Eye ointment & 14.43 \\
\hline Oral & 3.11 \\
\hline Parentral & 1.79 \\
\hline
\end{tabular}

Class of Drugs used

\begin{tabular}{|l|c|}
\hline Class of drug & Percentage \\
\hline Antibiotic & $20.87 \%$ \\
\hline Steroids & $4.11 \%$ \\
\hline Antiinflammatory & $3.62 \%$ \\
\hline Mydriatics & $17.24 \%$ \\
\hline Anaesthetics & $12.02 \%$ \\
\hline Antifungal & $1.03 \%$ \\
\hline Anantivirus & $1.06 \%$ \\
\hline Lubricant & $5.98 \%$ \\
\hline Antiallergics & $4.84 \%$ \\
\hline Antibiotic + Steroids & $13.48 \%$ \\
\hline Antiinflammatory + Antibiotic & $15.75 \%$ \\
\hline
\end{tabular}

\section{Discussion}

Historically the pharmaceutical and medical professions have devoted considerable time and efforts to the development and rational utilization of safe and effective drugs for the treatment and prevention of illness. There has been development of many new therapeutic agents which have made it possible to cure or provide the symptomatic control of many clinical disorders. However in many circumstances drugs are not used rationally for optimal benefits and safety ${ }^{4}$. Drug utilization studies are important for obtaining data about the patterns and quality of use, the determinants of drug use, and the outcomes of use. The WHO drug use indicators are highly standardized and 
are recommended for inclusion in drug utilization studies ${ }^{5}$. Therefore pharmacoepidemiology can be a powerful tool that can benefit patient and public health but only if used appropriately by providing the insights into various aspects of drug prescribing and drug uses. WHO organizes many drug utilization researches with the goal of rational prescription by various methods of auditing. ${ }^{6}$

After screening of 5668 prescriptions there is no sex predominance found. This showed that eye diseases are usually not sex dependent rather may have age related dominance. Empirical treatment in eye conditions is based on the likely etiology, the available medical treatment and the surgical treatment. In the OPD, patients were treated by the various drugs in different dosage forms and ongoing medical treatment was modified according to clinical response. ${ }^{7}$ The high use of antibiotics in OPD reflect the condition of poor sanitation, nutrition and prevalence of various infections in our region. ${ }^{8}$

Average number of drugs per prescription is an important index as it tends to measure the degree of polypharmacy. It provides scope for review and educational intervention in prescribing practices. In this study the average number of drugs per prescription was 3.234. It has been recommended that the limit of number of drugs prescribed per prescription should be two and that justification for prescribing more than two drugs would be required because of the risk of drug interactions.

When the various dosage forms were compared it was found that eye drops were commonly prescribed in OPD followed by ointments tablets, capsules and injections. This finding supports the use of topical preparation for treating eye disease as they have site specific action, less systemic absorption resulting in fewer side effects and convenient for patient use. ${ }^{9}$

The most commonly prescribed drugs are antibiotic either alone or in combination with antiinflammatory and steroids followed by mydriatics. As the study is conducted in tertiary care hospital there are more complicated and infected cases leading to more frequent use of antibiotics. Mydriatics are used for treatment and examination purposes both so its use is very frequent.

\section{Conclusion}

In this study we have concluded the overall rational use of drugs. In very few prescriptions duration of treatment was not marked. Few prescriptions were not cost effective. The use of generic name in prescription is important. Improvement through continuous education is desired on the part of prescribers to ensure a good standard of care.

\section{References}

1. Atanasova I., Terziivanov D. Investigations on antibiotics in a hospital for a one year period. Int J Clin Pharm Ther. 1995; 33: 32-33

2. Parjawal P. et al. Drug utilization pattern in opthalmology department at tertiary care hospital, Int. Res. J. Pharma. 2013; 4(8) : 205-210

3. Pradeep R., et al. Drug Utilization Study in Ophthalmology Outpatients at a Tertiary Care Teaching Hospital.

4. R.P.Kowalski,L.M.Karenchak,andE.G.Ro manowski, "Infectious disease: changing antibiotic susceptibility," Ophthalmology Clinics of North America. 2003. vol.16, no.1, pp.1-9

5. Jain AK. et al. Drug utilization study in ophthalmology outpatient department in a tertiary care teaching hospital of western Uttar Pradesh, India. Asian J Pharm Clin Res, Vol 9, Issue 1, 2016, 354-356

6. Jadhav PR, Moghe VV, Deshmukh YA. Drug utilization study in ophthalmology outpatients at a tertiary care teaching hospital. ISRN Pharmacol 2013;2013:768792

7. Banjara SK, Mudavath K, Bhukya KD. Pattern of prescription and drug use in ophthalmology out-patient department in a 
teaching hospital. Glob J Res Anal 2014; 3:92-93.

8. Jadhav PR, Moghe VV, Deshmukh YA. Drug utilization study in ophthalmology outpatients at a tertiary care teaching hospital. ISRN Pharmacol 2013;2013:768792

9. Rambhade S, Chakarborty A, Shrivastava A, Patil UK, Rambhade A. A survey on polypharmacy and use of inappropriate medications. Toxicol Int 2012;19(1):68. 